\title{
J
}

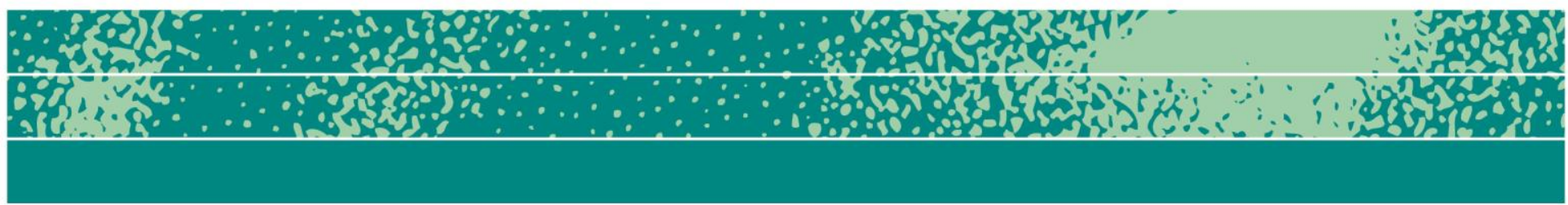

\section{The Senses in Anthropological and Marketing Research: Investigating a Consumer-Brand Ritual Holistically}

\author{
Timothy de Waal Malefyt
}

\begin{abstract}
The study of the senses encompasses a range of approaches from the social sciences and humanities. Anthropology, in particular, turns our attention away from previous considerations of the senses as biologically determined and universally fixed, to more interactive, adaptable and fluid concepts of the senses that are continuously shaped by culture, geography and history. Alternately, business marketers increasingly explore the senses and consumer's sensory response to brands as a means of eliciting deeper, more personal experiences with products and services. While anthropologists regard the senses as a form of social interaction, marketers seek to maximize consumer-brand relations by targeting specific sensory responses to consumption. This study integrates both views in an ethnographic investigation of a brand ritual. It examines the sensorial dimensions and symbolic associations of a shaving ritual that foster skills and reformulate time, which inform culturally situated notions of self-presentation and identity. This study advances a more holistic sensory approach to brand rituals as a means of enhancing consumer brand relationships and experiential consumption studies.
\end{abstract}

Page 1 of 26

JBA 4(1): 5-30 Spring 2015

(C) The Author(s) 2015 ISSN 2245-4217

www.cbs.dk/jba 


\section{Keywords}

Anthropology of the senses, brand, consumer behavior, ritual, sensory marketing

\section{Introduction}

The study of the senses, once the domain of psychology and studies on perception, has expanded to encompass a range of approaches from the social sciences and humanities. Disciplines such as anthropology have joined history, sociology, geography, design, religion, and cultural studies to reveal the extent to which the senses are constructed and lived variously in different cultures, subcultures, and historical periods (Howes 1991, 2003). Anthropology, in particular, turns our attention away from previous considerations of the senses as biologically determined and universally fixed, to more interactive, adaptable, and fluid concepts of the senses that are continuously shaped by culture, geography, and history (Bendix 2005; Brenneis 2005; Classen 1997; Geurts 2002; Howes 1991, 2003, 2005; Hsu 2008; Ingold 2000; Stoller 1989, 1997; Synnott 1991). For sensory anthropologists, the human sensorium, which straddles the divide between mind and body, cognition and sensation, is viewed as a cultural construction that is "socially made and mediated" in interaction (Hsu 2008:433). Anthropological investigations of the senses inform how culture-specific concepts and practices of sensory experience shape people's day-to-day interactions and mark what is meaningful in life.

Contemporary marketing also advocates that products of all sorts-from the advertising of bathroom fixtures to chewing gum, and fabric conditioner to cars-can evoke strong sensory responses and consumption experiences that appeal directly to consumers (Howes 2013). Krishna affirms that "products are sensual in nature... The more a firm can create, accentuate, or highlight the sensuality of their products, the more appealing these products can be for consumers" (2010:1). Creating sensations, or bringing attention to existing sensations, can increase the appeal of products or services to consumers (Hultén, Broweus and van Dijk 2009; Krishna 2010). Marketers view consumers' sensory response to brands as a means of eliciting deeper, more personal relations with products and services, and as a way to drive product purchase and enhance brand loyalty. The greater the number of sensory modalities stimulated at any one time, the richer the consumer's experience will be (Bahrick and Lickliter 2000; Schifferstein and Spence 2007; Spence 2002; Stein and Meredith 1993). The hope for marketers is to unite all the senses in a cascading effect and create a "supreme sensory experience" that wins over the consumer (Hultén et al. 2009).

This essay examines the rising interest in sensory approaches to consumer behavior. It incorporates sensory approaches of 
anthropologists that regard the senses as a form of social interaction, with marketing interests in the senses that seek to maximize consumer brand experience through targeting specific sensory responses to consumption. While an anthropological approach seeks a more holistic and integrative understanding of the ways that humans actively sense and make sense of their world, a marketing approach applies those experiences in terms of expanding consumption opportunities in novel ways. As a way to integrate these two theoretical viewpoints and develop a sensory-rich approach to consumer research, this essay investigates a consumer-brand ritual for a men's grooming product. Ethnographic analysis of a shaving ritual highlights the qualitative aspects of consumer sensory engagement, which are less available through marketing approaches of experimental design or statistical studies of the senses.

\section{Towards an anthropology of the senses}

Within the last two decades anthropologists have increasingly focused their attention on the human sensorium as a cultural category for investigation. In the 1980s and 1990s, an "anthropology of the senses" was established by the work of Classen $(1993,1998)$, Howes $(1991,2003$, 2005), Stoller (1989, 1997), Feld (1982), and Feld and Basso (1996). Sensory studies have since expanded to include a cultural history of the senses (Classen 1993, 1998, 2012), the sensual revolution (Howes 2005), sensuous scholarship (Stoller 1997), sensuous geography (Rodaway 1995), a sociology of the senses (Synnott 1993; Vannini, Waskul, and Gottschalk 2012), the senses and perception (Ingold 2000), senses of place (Feld and Basso 1996), the sensorium of contemporary arts (Jones 2006), sensory architecture (Malnar and Vodvarka 2004), sensory ethnography (Pink 2004, 2009), and ways of sensing contemporary society (Howes and Classen 2013) among other studies. While acknowledging different challenges to sensory studies, these views champion a more multi-sensory orientation towards theory, cultural understanding and fieldwork practices.

Sensory anthropologists distinguish themselves from those adopting other approaches to the senses by taking a decidedly social and cultural approach. Anthropologists claim that sensory experience is generated between and among people, places and events, rather than in an individual's body (Hsu 2008). As opposed to dividing the body and mind, and treating the senses as biological vehicles that merely channel information to the brain, anthropologists and sociologists regard the active interplay among sensory experience, emotion, memory, and cognition as deeply contingent upon situated meaning and context. Vannini and colleagues posit: "as we sense we also make sense" (Vannini et al. 2012:15). Scholars regard human sensing as an interpretive process, and therefore explore the interactive ways that the senses are socially patterned within culture; how the senses are culturally ordered and 
variously ranked across cultures; and the ways in which the senses are linked to emotion, memory, and experience.

Anthropologists note the ways humans attend to what is cued by culture, rather than hold that humans perceive and understand the same experience universally. In particular, anthropologists seek to learn how culture-specific concepts and practices of sensory experience shape people's day-to-day interactions and mark what is meaningful in life. This practice is indicated cross-culturally in consumption by what people may consider to be "good" or "bad" food, or by what is regarded as beautiful or not. In such interactions meaning is emergent and produced interactively among people, places, events, and materials, which vary by cultural context. Herzfeld (2001:244) explains that:

"To stare at someone may signify rudeness, curiosity, flattery, or domination, depending on the circumstances and the culture. Downcast eyes, in contrast, may suggest modesty, fear, contemplation, or inattention. And these are simply the possibilities for cultural coding, within which personal idiosyncrasies may produce further variation..."

The senses thus play a vital role in coding, producing and maintaining different perceptual modalities, which mediate daily experience and vary by culture and situation within culture.

\section{Cultural Orders and the Senses}

Anthropologists also investigate the ways that perception and the senses are ordered and ranked by cultural contexts and social interactions. The patterning of sense experience is not universal, but rather, "varies from one culture to the next in accordance with the meaning of and emphasis attached to each of the modalities of perception" (Howes 1991:3). People of one culture may prioritize the senses in particular hierarchies, with various associative meanings over other cultures. The Anlo Ewe Children of Ghana, Africa, for instance, incorporate all five senses-including a "sixth sense" of moral and bodily-enacted balance-to navigate their world, different from Western children who are taught to rely on vision and audition as primary modes for learning (Geurts 2002). In Papua New Guinea, the Kaluli people have developed fine acoustical skills to traverse the dense and visually obscure rainforests. Acoustic orientation to their world not only enhances Kaluli perceptual inputs, but also culturally structures folklore, dance and body décor (Feld 1982). In Indian ceremonies, the sensual concept of rasa blends the tasting of food and beverage with pleasure, leading to a heightened emotional appreciation of the entire event. Food, along with enjoyment of the ceremony, is literally and metaphorically "tasted, ingested, and excreted" in a "snout-to-bellyto-bowel" mixing of intimacy and shared bodily substances among audience and performers (Schechner 2007:10). The Songhey sorcerers of 
Africa learn power in healing rituals and history of their culture by "eating and tasting it, ingesting odors and tastes, savoring textures and sounds" (Stoller 1997:3). Even in Western culture, apparently "universal" color schemes can be politicized with alternative cultural meanings. Ireland, known as "The Green Isle," is variously identified in the different ways people "see green." Color is used as an identity marker, from the ban on the wearing of green during British colonialism, to green signifying the color of the Republican Revolutionary Organization, to green marketed in outsiders' construction of celebrating Irishness, such as turning the Chicago river green for St. Patrick's day and drinking green beer (Wulff 2011). These examples inform different modes of cultural perception, as culture-specific concepts and practices generate particular forms of social interaction for what is meaningful in life, how emotions are expressed, and how people should interact with material things.

\section{The Senses in Marketing}

Corporations are also increasingly paying attention to consumer experience through sensory modalities. "Sensory appeals are everywhere, they are increasingly personalized and they are intensifying," writes journalist Postrel (2003:5). Business consultants Hultén and colleagues posit that recent sensory awareness has launched "a new epoch in marketing," where "the five senses will be at the center of a firm's marketing strategy and tactics" (Hultén et al. 2009:2). Sensory marketing, they hold, supersedes mass and relationship marketing because it involves "heightened consumer involvement with objects on a personal level" (2009:5). The marketing belief is that the greater the number of a consumer's senses engaged, or the deeper engagement of a particular sense, the stronger an emotional impression is made between consumer and branded product (Hultén et al. 2009).

Marketing research confirms that consumers' heightened sensory experience results in increased engagement and greater emotional involvement with products (Krishna 2010; Schifferstein and Spence 2007). A cursory view in the field of scent demonstrates the range of specific effects of scent on product evaluation and consumer decisionmaking (Bone and Ellen 1999; Mitchell, Kahn, and Knasko 1995; Spangenberg, Crowley, and Henderson 1996). Scent can attract attention, evoke memories, and affect consumer decisions for items that are familiar and unfamiliar (Morrin and Ratneshwar 2000, 2003). Indeed, marketers note the ways that scent influences consumer memory for selecting certain branded products. In one experiment, scented pencils evoked greater recall from subjects than unscented pencils, even after a prolonged period of time (Krishna, Lwin, and Morrin 2010).

Marketing research on the senses also explores multisensory combinations or consumers' cross-modal sensory responses. Experimental research on multisensory experience shows the powerful 
effect of congruence between touch and smell, such that the input of one sense affects a consumer's perception of another sense, as in scented gel packs perceived to aid in the treatment of pain (Krishna, Elder, and Caldara 2010). In another instance, researchers discovered the relationship between perceptions of touch and taste: for example, that mineral water served in firmer cups tasted "better" to subjects than water served in flimsy cups (Krishna and Morrin 2008). Other experiments have focused on consumer response to visual written information and verbal system processing (Paivio 1971, 2007). Humans respond "better" to active pictures that enhance their memories and thus affect their behavior. For instance, imagery of dynamic action built into signs can influence consumers' perceptions and reactions, affecting their responsiveness to various signage (Cian, Krishna, and Elder 2014).

Nevertheless, sensory anthropologists may inquire how these structured investigations might be contextualized and applied more holistically to everyday consumer situations. When, for instance, does everyday consumer enjoyment of a brand begin, and what are the sensory dimensions that subjectively lead to positive "peak experiences" (Privette 1983)? A sociologist recalls his total enjoyment of coffee as greater than any one, two or several isolated sensory cues that might be evaluated separately:

"I genuinely enjoy the total sensual experience of fresh-brewed morning coffee. The taste of coffee incorporates its smell, but the smell of the coffee I drink is quite different from the tantalizing aroma of brewing coffee, a scent that, in fact, seems to awaken my senses... I know that the smell of brewing coffee anticipates and lubricates how I both taste and smell coffee when I drink it... [T] he flavor of coffee also includes the feel of hot liquid. In the morning, it has to be hot. I occasionally enjoy iced coffee, but iced coffee would never satisfy me in the morning, regardless of environmental temperature. Even the weight and feel of the mug are significant. I find it hard to get a satisfying swig from those dainty, undersized, bourgeois espresso cups..." (Vannini et al. 2012:5).

In this instance, the taste, smell, weight and temperature of coffee, in addition to morning time, blend into a full sensual, contextual, and temporal coffee experience, not reducible to isolated variables in experimental design or laboratory settings. Applying contextual features to sensory inputs expands our knowledge of what perceptual features make a beverage enjoyable, and under what social situations they occur. Marketing researchers note in controlled studies that sensory interactions influence consumer visual perceptions, such that taller glasses appear bigger and to hold more liquid (Krishna 2012), or that the texture and feel of the glass impacts impressions of quality and taste (Krishna and Morrin 2008). Nonetheless, how might these insightful sensory revelations in controlled settings be applied more broadly to 
everyday consumer experiences? Coors, for instance, uses cold-activated bottles and cans, in which the visual imagery of the mountains on the label turns from white to blue when the container is at the proper cold temperature (Elliot 2009). The Guinness "ritual" involves multiple sensory touch points, sequencing six steps to drafting the "perfect pour" that join haptic, visual, gustatory, and temporal cues-from holding the glass at 45 degrees to pouring for a duration of 119.5 seconds (Guinness Storehouse). How might consumer studies of these sensory dimensions of beer enjoyment reveal other perceptual meanings under different social settings?

Addressing the lacuna in holistic sensory experience, this article seeks to inform sensory studies along the lines of everyday consumer practices. In particular, domestic rituals of consumers are one such practice by which cultural relevance, sensory order, temporality and situated meaning, along with human sensory variance to product use and enjoyment, frame consumption in terms of everyday situations. Marketing researchers have examined everyday experience along multisensory lines to elaborate deeper dimensions of art appreciation in museums (Joy and Sherry 2003). Other ethnographic investigations of consumers' sensory reactions to homecare products include the study of scents of detergents, commissioned by Lever Brothers (Pink 2004). A study of daily rituals, this essay claims, can join sensory, temporal, symbolic and communal dimensions of consumer experience to afford a holistic framework by which researchers can more deeply investigate products and brands in everyday settings.

\section{Ritual analysis}

Anthropological studies have long examined ritual for its cultural representations of social phenomena, such as mitigating sacred and profane cultural boundaries (Douglas 1966), enacting social dramas to resolve conflict (Turner 1967, 1969), or performing grand political displays of power (Geertz 1981). From its functional role in maintaining social solidarity (Durkheim 1912/2001) to mystifying society for perpetuating dominant hierarchies (Eliade 1998) to offering transcendent religious ideology for its members that translate enduring messages, values, and sentiments into observable action (Rappaport 1979), numerous investigations have explored ritual for its sacred, religious and ideological dimensions. Indeed, Bell's $(1992,1997)$ thorough historical review of ritual informs us that numerous anthropological theories, from Evolutionism to Post-Structuralism and beyond, employ ritual analysis to evidence their particular approach to cultural and theoretical analysis.

Appositely, consumer researchers of ritual have shifted their focus away from larger symbolic meanings in religion, cosmologies and belief systems to examine, instead, its everyday occurrence. Whether highly 
stylized, or casual and informal, Rook situates ritual as "expressive of symbolic activity" in everyday life (1985:252). Goffman's "sociology of occasions" (1967:2) explores how rituals are performed in ordinary occasions and employed strategically to organize daily face-to-face social interactions. Sherry's seminal work on everyday gift exchange highlights rituals in "naturalistic" settings of shopping occasions (Sherry 1983). Indeed, rituals are broadly evident in consumerist society and are found in production, such as in aiding the internal development of commercial advertisements in ad agencies (Malefyt and Morais 2010), and in consumption, where they may organize food preparation and consumption (Farb and Armelagos 1980), mediate Christmas myths (Miller 1995) and consumer spending patterns in Japanese culture (Moeran and Skov 1995), or celebrate Thanksgiving's "material abundance enacted through feasting" (Wallendorf and Arnould 1991:13). Rituals also moderate consumer activities such as travel and tourism (Graburn 1977, 1983; MacCannell 1976), and exchanges between buyers and sellers at local festivals, swap meets, restaurants and museums (Belk, Wallendorf and Sherry 1989). In these and many other examples, rituals share a property of transforming participants from one (emotional) status to another by moving them through symbolic space (Douglas 1966; Turner 1969). Importantly, this transcendent property distinguishes ritual from ordinary repetitive habit, since "standardized, repetitive action lacking such symbolism is an example of habit or custom, not ritual" (Kertzer 1989:9). Yet, missing from these and other ritual studies are the attendant sensorial dimensions that concomitantly deliver transformational experiences for participants.

From a sensory approach, rituals are observable practices (Bourdieu 1977) that, in addition to being symbolically rich, are "something experienced in the doing" (Senft and Basso 2009:3). Rituals are symbolic action "thick with sensory meaning" (Grimes 1995:965). Moreover, they arouse in the senses a particular quality that "awakens alertness" (Hsu 2008:439). Rituals are intentional sequences or series of behaviors that reformulate experience out of existing materials (Schechner 2002); and therefore may be examined here as situated practices that employ both sensory qualities and symbolic meaning to reformulate a new sensory/symbolic order for participants. This study explores ritual as an everyday practice that informs personal transformations through sensory skill development and symbolic associations, which orient socialized constructions of self-identity in the world.

\section{Methodology, rituals of shaving}

In 2010 ethnographic research was conducted among twenty-four men aged 18-49 in the New York, New Jersey, and Connecticut region of the US. Research was conducted on behalf of a men's hair-care and grooming 
company by an anthropologist (the author) of an advertising in-agency ethnographic group. The hair-care company had recently purchased a premium-priced shaving brand and sought to understand why a segment of men who regularly purchased this brand spent more time and money on shaving equipment, appeared to develop strong brand affinities, and shared their opinions and experiences with other men in online communities, when the majority of men disliked shaving and were reluctant to spend a premium on shaving equipment. In other words, who were these high-involvement shaving enthusiasts in a consumer category that is notorious for low-involvement? The research objective sought to bring these shaving enthusiasts to life.

Men were pre-screened by a market recruiter for attitudes and behavior towards grooming and product use. Half the men recruited expressed positive attitudes towards shaving and purchased the premium brand, while the other half disliked shaving and purchased a minimum of grooming products. Ethnographic interviews were conducted in the homes of the 24 men and lasted for about three hours. Interview questions were formulated around general attitudes towards shaving, appearance, and use of grooming products. In-home research included observing men demonstrate their shaving equipment and grooming regimens.

Curiously, what made the brand a ritual for the shaving enthusiast was not explicitly the brand advertising and packaging, which stipulates a 4-step order of pre-shave moisturizing, lathering, shaving and aftershave, leading to the perfect shave. Rather, the ritual was developed and improvised by the men themselves, who described a personal interest in grooming and personal care. These men evidenced a strong predisposition toward ritual involvement in their attitude toward self, work and others, prior to discovering the shaving brand. They embraced what might have been routine behavior, and made the brand more sensorially engaging and personally fulfilling by adding their own refinements and by developing their own skills; they made the brand more meaningful emotionally with their own symbolic references. Without a predilection for self-improvement, explorations into shaving that fostered skill development and augmented the ritual would not have occurred. In other words, by blending various aspects of time, effort, symbolism, and branded materials into sensorial practice, their practice became a ritual in the "making" (Ingold 2013).

This investigation of a men's brand ritual posits that the extended experience of engaged effort applied to sensorial perceptions, personal care, brand materials, setting and symbolic references, leads to personal transformation and ritual development. Ethnographic interviews with shaving enthusiasts examine here the process by which ritual behavior becomes a unified experience in: 1 ) consumer pre-dispositions towards appearance and self-presentation; 2) skill development through sensory 
awareness; 3) meaningful symbolism evoked through memories; and 4) discursive vocabularies and shared skills that fostered online communities.

\section{Presentation of self to others}

Among the shaving enthusiasts interviewed, appearance was central to their sense of self and to perceptions of performance in the world. Beyond solving a functional problem of providing a close shave, their descriptions revealed deeper, more engaged interactions with the entire grooming process. Clothes, hair and shaving played a key role in defining who these men were in terms of self-identification and performance in the world. Attention to daily attire and grooming were essential practices in their "presentation of self" to others (Goffman 1959). These men also expressed a higher level of satisfaction with shaving, compared to the other men we interviewed. Alternately, the low-shaving involvement men spoke of shaving as "a chore," of skipping days, and minimizing their time and money spent on shaving. Men who disliked shaving referenced the positive aspects of shaving mostly in terms of completion-in "getting it done"-or in the absence of negatives (no nicks or cuts). In contrast, the shaving enthusiasts discussed the "extra shaving effort" as a form of future payoff. Their increased effort in grooming and appearance led them to feel like "better" men, in what they described as a performanceoriented, competitive work world:

Frank, a 29-year-old attorney explained: "We have casual Friday instituted at my office. People walk around in jeans. But I don't do it. A tie is not expected, but I like to go above business casual. People my age don't care, but the senior people do, even if they don't say it. The way you dress affects the way you behave. I feel more comfortable, competent and ready. When I'm dressed right, I feel ready to meet people and do things."

Jeremy, a 28-year-old grade school teacher elaborated: "Most of the teachers at my school are in jeans and a polo shirt. I'm usually overdressed compared to them. I act more mature and feel more mature when I'm wearing dressed clothes. It affects me and the mood I'm in. I feel like accomplishing more. When I was in student government, I would also dress up going to meetings. It would affect how people listened to me. Depending on meetings in school, I dress to the position of power. I feel it's reflective of my position."

Another respondent, David, 35 year-old legal aide commented: "People tell me 'nice tie' and it feels good! If you want respect then it not just acting it, but looking it. You have to dress the part! To look good is a form of respect... It's not shallow, you feel better, more confident. When you get up in front of people, you can see that he's confident even when... say, if he's dumb (laughs). The 
cover of a book is more interesting than what's inside."

Joseph, 49 year-old technology manager at a local NJ college explained: "I wear a tie to work. It adds to the professionalism. People are then dealing with someone, not just 'a guy.' It adds to the sense that you are someone, doing a job well done. People respect you more when you have a shirt and tie. I don't want to look like a common slob. People treat me differently. Clothes make the man, and well, a close shave makes the man, too. I like to be formal... People tell me 'nice tie' and it feels good. If you want respect, then its not just acting it; you have to look it. I'm indulging myself, but it's a necessary indulgence."

As these comments reveal, men's heightened involvement in appearance is evident in their responses to work, dress, and the role of grooming in their lives. Attention to appearance and dress not only transformed these men to be "ready for the day," but also identified them as men for whom care and attention to appearance were important for success at work. In this regard, the practice of morning shaving translated into enhancing the social self and influencing concepts of success in the world.

\section{Sensory dimensions of ritual skill}

Shaving enthusiasts also informed us of their increased attention to sensory inputs. Men spoke of being "more aware" in the steps of what they were doing while they were shaving. Men attuned to various aspects of the brand with greater acuity. In the packaging, they identified the glass container, script writing, list of natural ingredients, and set of directions as features that enhanced the brand's value to them. Men further described the importance of sounds, movements, textures, feels, and scents in their daily practice of shaving as helping them develop skills. Some men enjoyed stirring the brush and "frothing up the lather," and applying scents of lavender, sandalwood, ocean kelp, or eucalyptus and citrus. Still others described listening to special mood songs, such as ones by Frank Sinatra, or using no music at all, and attuning to the sound of the blade gliding over the skin, touching one's face for assurance. The sensory dimensions of the brand features joined behavioral skills to aid in the transformation of the self:

Joseph, the technology manager commented: "I have to shave in the morning, every morning. It wakes me up... it lifts me up. The warm lather on my face, I enjoy it. A good shave is a good start to the day... I can't shave with music. The audible feedback of the blade gliding on the skin is tremendous. I enjoy the feedback of it. It's like comparing the sound of a Harley to that of a Vespa. You learn to recognize the right sound, the sound of your equipment, and you know you are doing it right."

Peter, a website developer in his early 20s remarked: "I used to hate 
shaving. Then I learned about (the brand) and it's a nice, pleasing way to start my day. To me, my morning routine helps wake me up. There's an olfactory component to it, like smelling morning coffee or soap in the shower. This is another experience like that. I use the eucalyptus citrus smell. It kind of smells like an old fashioned barbershop and there is something invigorating about that. I find it pleasant every morning."

Men also tuned to the brand's visual signals, such as the cursive serif fonts on the packaging, with more acuity. Some spoke of the moisturizing preshave lotion packaged in a heavy glass jar as being more "old-fashioned" and "genuine" than if it were made of plastic.

A grade school teacher, Paul, explained: "This (the brand) has utility, but there's more aesthetic to it. It's like a grapefruit. You have to meticulously cut out the little pieces. The little bit of labor makes it more rewarding at the end. This takes time, the art of shaving is like art and isn't just slapped together. It takes time... it puts me in the mood of accomplishing something."

He added: "This may look more complicated than it is. It takes four steps to it, but there is a benefit in the complexity. It's really not that complicated. The benefit of the brush is that you enjoy the fruit of your labor. You are creating the air, the foam, the fluffiness, and you're putting it on and know it's going to work. It's like making coffee. I get raw beans, grind them up, then add the water, and wait. This is a couple of extra steps, but you get the benefit of having a better shave."

In the process of enjoying the brand and the shaving experience, these men also drew out the best of its qualities by adding their own skills. Beyond following the four-step process, some men embellished the ritual sequence, adding refinements to enhance the sensory experience. One man spoke of adding a few drops of olive oil to the shaving lather to "further soften whiskers." Another man pre-warmed a frothing cup with hot water for "better foam." These men demonstrated greater focus, selfawareness and judgment, which led to skill in developing their overall appearance. Skill is experiencing new sensations in familiar patterns by "fine-tuning" perceptual systems to new kinds of information (Ingold 2000:166). In this way, shaving skill embodies a situated sensory practice for a new self to emerge.

\section{Shaving rituals as symbolic "time machines"}

Men also related their current shaving practices to past memories, images and reminiscences, real and imagined, which drew them into sentimental experiences with shaving. Shaving was a symbolic link to other places, times and memories of significant others in their lives. 
Paul commented: "When I go to the (the brand) store and purchase the Royal Shave, it carries a regality to it. When I use it I'm reminded of old-time traditions. It means to me someone that is experienced, meticulous, and effective. It's sort of the British banker world in the 1900s."

David, a 35 year-old attorney mentioned: "My sister got me a gift certificate and I went to (the brand) store to get a shave. The store felt old fashioned, a real plus. Shaving is not a new thing. Men have done it before and have an edge in doing it. I can picture my grandfather doing it, just like I am doing it today."

Frank, a 29-year-old attorney, said: "This reminds me of the time of my grandparents, of going to barber shop. The barber was a professional, like a physician. That is all they did, all the time. This (the brand) feels more professional. This makes me a professional." Joseph, a 49-year-old technician waxed nostalgia over manual shaving. When shown an electric brush prototype that would have eased shaving, he remarked: "Please don't say it's a battery operated brush. It defeats the whole purpose of shaving. There's a sense of accomplishment in using the brush, and making your own lather. The minute you put a battery in it, it's like you're not doing anything. You're then letting the machine take over once again. Machines do enough for us. (Instead) it's a sense of identifying with your dad and granddad. You're doing something the same way that they did it. It's sort of a bond, even though they are not here with us. It's a sense of identifying with them."

Citing the work of Levi-Strauss, Miller (2009), relates the symbolic use of time in rituals as effective "time machines." Like a time machine, regular repetitive rhythms of ritual "suppress the linear narrative of unstoppable time that ultimately marches on and leads to our end," and draws men into a cycle of timelessness. The repeating of a common routine "makes it timeless, and oneself in it, timeless too" (2009:165-6).

Moreover, branded objects stand as symbolic vehicles to further draw men into the ritual circulation of the time machine metaphor. Objects stand for particular lives or experiences of familiar others (for instance, "my grandfather used to shave with a brush," or "use a double edge razor"), which keep alive not only items, but also personal memories of others. Ritual activates an emotional context via scents, gestures, feelings, and images that place men within re-lived experiences. The sensory experiences activated in daily rituals help "reproduce regimes and routines" of the mediated self in "temporal textures" of everyday life (Strove, Trentmann, and Wilk 2009:5).

\section{Communicating rituals via online communities}


Shaving enthusiasts also discussed their brand preferences, shaving techniques and experiences with other men in online shaving sites. From discussions with others, men developed new linguistic descriptors and shaving vocabularies, in which they described particular sensations, evaluated experiences, and shared insights on product features.

Men spoke of the importance of facial hair being properly "hydrated" so as to "reduce pull" and "drag," and "limit ingrown hair irritation." Men also discussed "shaving in passes," "letting the weight of the metal razor" do the work, "working with the grain" and not "bearing down." Others described "unlearning bad habits of rushing," or "using 3045 degree angle," and "rocking the blade down to proper angle." Others described the "deep satisfying sound" of shaving with a heavy metal blade, versus a light sound of plastic blades.

Men also debated the numerous single blade options. Among them were fixed head and adjustable razors, and three piece, two piece, and one piece razors that hail from the Middle East, Japan, or Germany. Some discussed vintage single blade razors, such as Gillette's "Super Speed" models from the 50s and 60s. Other brands discussed were Personna blades from Israel, Derbys from Turkey, and Feathers from Japan. German Merkurs were debated as "the standard," whereas Japanese Feathers were discussed as "the sharpest blade for experts."

As men communicated shared experiences, discussions helped strengthen their own brand opinions and personal experiences of shaving. Online discussion of shaving then becomes a "circulation" of various experiences and perspectives across subjects and distant spaces (Senft and Basso 2009). Rituals help synthesize difference in geographies and backgrounds through a common "translation" of experience across communities.

Evident here, shaving enthusiasts develop skills and a repertoire of linguistic distinctions that enable them to enhance their experience. Differentiating stimulus properties also lets men develop more finely tuned preferences (Cooke, Janiszewski, Cunha, Nasco, and De Wilde 2004). In online shaving groups, men discuss techniques and skills, and compare one brand's characteristics to another. Learning an acquired skill that can be traded and shared has the potential to expand online relationships and sociability (Kozinets 2009). Also, by generalizing a "point of view" (Oakdale 2009:162), discussion offers a means of producing alignments of perspectives, even as men express differences that effectively negotiate new social relations and new types of social identities (Senft and Basso 2009).

\section{Discussion: Contextualizing a holistic experience through time and skill}

This study investigates the somatic interactions of human "sensing and 
sense-making" (Vannini et al. 2012) with time, effort, context and material culture, such that a study of the senses would be incomplete without examining the larger context of interactions.

A sensory account of ritual incorporates the multiple "agents" that shape a holistic experience of interaction, joining the pleasure of experience with the effort of exertion in what Borgmann (2000:420) terms a "symmetry of experience." Just as people interact and manipulate everyday objects to suit their needs, objects also shape people in prompting certain responses from them (Latour 2007). In this investigation, certain men choose a premium-priced shaving brand from among the plethora of grooming products available to them, because the brand does more than function efficiently; it requires of them increased time and focused effort that, in return, awakens sensual pleasures and memories, and fosters skills (Ingold 2000), which relate to socialized concepts of the self.

Meaningful symbolism and sensory experience coalesce in ritual exertion. What objects prompt from users in ritual effort not only promises to enhance their sensory experience in the present, but also to transform, or at least activate, their memories of the past. Since "sensing is thinking" (Vannini et al. 2012:152) the ritual act of shaving initiates meaningful thought for consumers. Memory in shaving rituals responds as a "culturally mediated practice that is activated by embodied acts and semantically dense objects" (Seremetakis 1994:90). Evocative scents, images, actions of lathering up foam, the morning time itself, reveal a congruence of multiple factors that coalesce in a unified experience of "focal things and practices" (Borgmann 2000) not reducible to the effects of one or several isolated senses or symbolic associations. Interactions are layered and intermingled with context and action, so that "the memory of one sense is stored in another; that of tactility in sound, of hearing in taste, of sight in sound... The awakening of the senses is the awakening of the capacity for memory, of tangible memory; to be awake is to remember, one remembers through the senses, via substance" (Seremetakis 1994:28). A sensory study of consumer rituals thus joins physical effort, material objects, and symbolic analysis in a symmetrical view of consumption.

The multiple effects of symbolic and sensory symmetry can be analyzed further in terms of time practices, skill acquisition and online communities, which add to the holistic ritual experience of shaving.

\section{Time as a ritual practice of agency}

Consumers in everyday life often refer to time as an agent that operates against them. Expressions of being rushed, feeling "time-poor," or "out-oftime," are references to something outside of their control and shaped by external forces (Strove et al. 2009). However, this study shows that some 
men "make time" to organize daily rituals and consumption practices by creating "focal practices" with "things" in time. For these men, the daily ritual of shaving makes time, where branded objects "play a critical role as a kind of compass or clock across their life course" (Strove et al. 2009:6). These men use material objects, such as brands, as "communicators and stabilizing devices which they employ to attain, reproduce and challenge temporal identities" (ibid.). One such temporal identity constructed through ritual is the presentation of self (Goffman 1959), which is organized by time, effort, and skill into an agent of "success" in the world. Time and effort in shaving are characteristic of a practice that orders and organizes sequential rhythms of ritual into perceived outcomes of success in the world. We can further examine types of temporal practices of "making time" into concepts of "success."

Ritual activates symbolic associations of "time as success" in ways that operate both retrospectively and prospectively (Senft and Basso 2009). In this study, men use a shaving ritual to "look back" in time to other persons and ideals, but also, at the same time, "look forward" to anticipate future outcomes (Hirschman 1987). In looking forward, men take time in shaving to anticipate success in the competitive work world. Time spent grooming in the morning is not time lost, but rather leads to a better "presentation of self" at work (Goffman 1959). Time and effort thus anticipate a future reward of a better self in a cultural category that projects male performance as a form of display in the work world. Time spent shaving also references retrospective constructions of heritage (Hall 1983; Zerubavel 1981) that are oriented towards past images of success. Men in this study referenced symbolic linkages to traditional images of male success, such as the "experienced, meticulous, and effective... British Banker in the nineteenth century," or "the professional barber," who, in turn, makes them "professional." Time, in this sense, recategorizes the effort of ritual practice into "active metaphors" (Cotte, Ratneshwar, and Mick 2004) that reference Western cultural markers of success in the world. The sensory aspects of the shaving ritual thus generate time-practice as a marker of success in the world by anticipating a better future self at work and a past heritage of success, adding to the "symmetrical experience" of exertion (Borgmann 2000).

\section{Skill as a ritual practice of agency}

Ritual action carried out in sensory practice also fosters the development of certain skill sets that lead to constructions of success in the world. The acquisition over time of consumer sensory skills, such as holding the blade at a proper angle, listening to different sounds when moving the blade across skin textures, adding emollients to foaming cups to further soften whiskers, are active practices of skill development that create "an education of attention” (Gibson 1979:254). Beyond merely increasing perceptual awareness, the continual refinements of hand motions, 
holding positions, and facial postures in shaving rituals has the effect of "fine-tuning" the shaver's physical effort in novel acts of creative discovery, beyond following rote instructions or simply imagining an outcome.

The development of skill, which Ingold describes (2000:352-4), can be further analyzed here as a distinct characteristic of shaving ritual skill. First, skill is the applied effort of mind, body, and senses all holistically working together. The intentionality of shaving and functionality of carrying out steps are brought into use congruently, not one first or the other: mind and body, perception and sensing, work harmoniously in a total experience of shaving. Second, skill is highly contextual of engagement with its surroundings. Ingold references Bateson's example of the woodcutter at work notching a tree in a whole man-axe-tree system (Bateson 1973:433; in Ingold 2000:352-3). Likewise, men in this study create a whole man-blade-shave contextual system that encompasses an entire field of relations of morning time, effort, situation, and attention in practice. Third, skill involves more than heightened attention and sensory awareness of behavior. It requires specific care, judgment, and dexterity applied to an ongoing process of "hands-on" training. Initial concern for appearance led these men to develop care and attention to grooming skills, which fostered judgment over how they looked in presentation of self to others. Fourth, skill carries its own intrinsic intentionality and reward in its practice, apart from pre-set ideas or plans before it. In other words, skill and pleasure unfold each time in the doing that is not reducible to some pre-existing formula. Fifth, skill is, therefore, an act of "making," which generates its own reward that is pleasurable as an integrated mind, sense, and body experience (see Ingold 2013). As skill in a product category increases, consumers can better appreciate, and therefore get more out of, the consumption experience (Clarkson, Janiszewski, and Cinelli 2013).

\section{Communal practices of agency}

Developing skill in brand rituals also offers a sensory framework for increased enjoyment in terms of sharing experiences with others. This includes distinct opportunities for communal participation, structure, discursive themes, pragmatic outcomes, and processes (Basso 2009:1617; Oakdale 2009:153). Wine connoisseurs, for instance, develop an appreciation for wine that sets wine tasting apart from everyday drinking. Tasters of wine "become aware" of the special qualities, not only of the wine, but also of their group (Vannini et al. 2012:54; also Schechner 2002). As a shaving community, men not only discuss shaving results, but also sensory awareness comes to the fore, placing expectations on shaving performance and equipment, and expressing an evaluative judgment on the qualities of the shave experience. Similarly, the "Burning Man" community in Kozinets's (2002) ethnography, and the "Mountain 
Men" of Belk and Costa's (1998) investigation, disregard commercial structures to create their own community of fellow participants with cocreated skills in which these activities occur.

A shaving ritual thus can elicit the holistic dimensions of practice that coalesce in a context of pleasure. Applying sensory skills of shaving within a temporal, skill, and social framework, places greater expectations on judgments of the products so that brands "perform" beyond their functional role. Providing pleasure to consumers rejoins brand features in a temporality and effort of occasion. Uniting the full range of sensory cues with heightened awareness of symbolic associations means that rituals reformulate experience in ways that create a new order out of existing materials (Schechner 2002). Ritual is therefore not merely "acted out," or "performed," as in some pre-existing mental text or script. Rather, time and effort occasioned in bodily practice bring skills into use in-the-moment, through sensory involvement and pleasure. The anticipation of shaving becomes a "forward-oriented process," inviting forms of improvisation and minute adjustments to the person's own rhythm (Hallam and Ingold 2007). This creates an emergent experience in a consumer brand practice that may continually grow and give pleasure to the user.

This investigation of a men's shaving practice affords a new approach to ritual. In this study, ritual is not a disembodied metaphoric projection acted out as a pre-existing mental schema (Lakoff and Johnson 1999), or a rote social pattern followed automatically (Durkheim 1912/2001). Rather, it is an individualized practice, situated in time and sensory enjoyment that proceeds along in thought and feeling through movement (Sheets-Johnstone 1999). Branded materials, bathroom setting, temporality of morning, skills of the enthusiast, as well as symbolic associations of memory evoked in scents, textures, weight and feel of product materials, carry a precision in their embodied manipulation that "corresponds" (Ingold 2013) in a natural "symmetry of exertion." This leads "focal practices and things" to unite in a pleasurable whole experience (Borgmann 2000:421).

\section{Conclusion}

This article has explored the interactive ways humans "sense and make sense" (Vannini et al. 2012:15) in a consumer brand ritual. It has argued that rituals develop through a set of sensory practices, temporality, skills, and situated use of material objects that inform an orientation and attitude towards work, life, and social relations. Individual sensory practices lead to skill development, a sense of self-confidence, performance, and outlook on life in an everyday activity. Even assemblies of online communities are involved in further shaping sensual rituals. This occurs because of the characteristic ways in which an individual is socialized in a particular culture to perceive and interact with materials, 
ideas, and other persons. How social orders shape sensory orientations is profoundly linked "with a society's epistemology, the development of its cultural identity, and its forms of being-in-the-world" (Geurts 2002:2356). A sensory orientation to personal rituals represents a critical dimension of how culture and psyche continually interact to "make each other up" (ibid.:236).

In this study, men's concepts of self, ideas of identity and success, and relations to others join commodity objects in a premium shave brand to form a holistic ritual process that is part of a social transformation, which displays sensory consequences. In Western society, concepts of success and identity are ideologies rooted in material culture (Miller 1995). Concepts of success here are not associated with intangible values of consumption, but rather given meaning in sensory practices that men believe help achieve certain and necessary personal transformations in appearance and self-confidence. In this study, extra effort, temporal procedures, acquired skills, and symbolic images are applied earnestly in ritual practice towards an everyday transformation, which is a viable means of reconfiguring the self by sensorially attuning bodily habits into a mode of performance, self-improvement, and perceptions of success in American society. Such notions evidence in modern capitalistic society the existence of particular sensory orientations and sensory orders that are practiced by men in daily rituals to transform the self.

\section{Future Implications}

It appears we are in the midst of a major social transformation in which a growing virtual world of digital relationships is replacing, or at least modifying, tangible relationships with people, places, things, and events (Horst and Miller 2012). The so-called "socio-digitization" of society reflects the wholesale transformation of a geophysical world into digital representations, where new technologies are reshaping social relations and constituting new social domains on a global scale (Latham and Sassen 2005). Perhaps this study of a group of men engaged in a premium, ritually involved shaving brand reveals a counter-practice that resists such ubiquity of digital representations and involves, instead, situated pleasures, acquired skills, and physical presence in real time. Against rising digital transformations found in the use of mobile devices, social media, chat rooms, and online dating sites that no longer allow direct access to the world through our senses, a sensory-based ritual practice, of the kind discussed in this study, may be one means for consumers to relocate the self in real time, engaged in a range of temporal sensory activities for the simple pleasure of it. Rather than acknowledge that the human environment is transforming wholesale into a digital environment, we need more investigations to show the countervailing measures and resistant consumer movements, such as the slow food movement and alternative eating practices (Pollan 2008), or community- 
supported agriculture practices (Thompson and Coskuner-Balli 2007), that are informed by traditions, fostered by acquired skills, and that celebrate sensory-based orientations of pleasure, such as found in this consumer-brand investigation of a daily ritual.

An "anthropology of the senses" (Howes 1991, 2003) does not leave off where marketing science begins. An anthropological study of the senses can integrate consumer behavior studies within a holistic perspective of adaptive representations of ourselves to ourselves through meaningful sensory and temporal practices, such as brand rituals. The cultural inclusion of the senses in various contexts of daily consumption illustrates the active, interpretive, and continuous engagement of the human sensorium with the process of meaning-making that occurs between consumers and brands, people and environments, memory and practice, and individual and community. Such studies can better inform consumer researchers the ways in which "the senses mediate the relationship between self and society, mind and body, idea and object" (Bull, Gilroy, Howes, and Kahn 2006:5). Investigations of holistic relations among consumers, brands, and everyday ritual practices disclose the rich sensorial world of pleasure about us that centers our lives and those of consumers.

\section{References}

Bahrick, L.E., and R. Lickliter 2000 "Intersensory Redundancy Guides Attentional Selectivity and Perceptual Learning in Infancy,"

Developmental Psychology, 36:190-201.

Bateson, G. 1973 Steps to an Ecology of Mind, New York: Chandler Publishing Company.

Bendix, R. 2005 "Introduction, Ear to Ear, Nose to Nose, Skin to Skin: The Senses in Comparative Ethnographic Perspective," Etnofoor, 18 (1):3-14.

Belk, R., J. Sherry, and M. Wallendorf 1988a "A Naturalistic Inquiry into Buyer and Seller Behavior at a Swap Meet," Journal of Consumer Research, 14:449-470.

Belk, R., M. Wallendorf, J. Sherry, M. Holbrook, and S. Roberts 1988b "Collectors and Collecting," in Advances in Consumer Research, ed. M. J. Jouston, Provo, UT: Association for Consumer Research, 548-553.

Belk, R., M. Wallendorf, and J. Sherry 1989 "The Sacred and the Profane in Consumer Behavior: Theodicy on the Odyssey," Journal of Consumer Research, 16:1-38.

Belk, R., and J.A. Costa 1998 "The Mountain Man Myth: A Contemporary Consuming Fantasy," Journal of Consumer Research, 25:218-40.

Bell, C. 1992 Ritual Theory, Ritual Practice, Oxford: Oxford University 
Press.

Bell, C. 1997 Ritual, Perspectives and Dimensions, Oxford: Oxford University Press.

Bone, P., and P.S. Ellen 1999 "Scents in the Marketplace: Explaining a Fraction of Olfaction," Journal of Retailing, 75 (2):243-62.

Bourdieu, P. 1977 Outline on a Theory of Practice, Cambridge: Cambridge University Press.

Borgmann, A. 2000 "The Moral Complexion of Consumption," Journal of Consumer Research, 26:418-422.

Brenneis, D. 2005 "Afterward: Sense, Sentiment, and Sociality," Etnofoor, 18 (1):142-149.

Bull, M., P. Gilroy, D. Howes, and D. Kahn 2006 "Introducing Sensory Studies," Senses and Society, 1: 5-8.

Cian, L., A. Krishna, and R. Elder 2014 "The Evoked-Dynamism Effect, Dynamic Imagery from Static Brand Logos," Journal of Marketing Research, 51:184-197.

Clarkson, J., C. Janiszewski, and M.D. Cinelli 2013 "The Desire for Consumption Knowledge," Journal of Consumer Research, 39:1313-1329.

Cotte, J., S. Ratneshwar, and D.G.Mick 2004 "The Times of Their Lives: A Phenomenological Inquiry on the Nature and Role of Consumers' Timestyles," Journal of Consumer Research, 31 (2):333-345.

Classen, C. 1993 World of Sense, London: Routledge.

Classen, C. 1998 The Color of Angels, London: Routledge.

Classen, C. 2012 The Deepest Sense, Champaign: University of Illinois Press.

Cooke, A., C. Janiszewski, M. Cunha Jr., S.A. Nasco, and E. De Wilde 2004 "Stimulus Context and the Formation of Consumer Ideals," Journal of Consumer Research, 31:112-24.

Douglas, M. 1966 Purity and Danger, London: Routledge.

Durkheim, E. 1912/2001 The Elementary Forms of the Religious Life. Oxford: Oxford University Press.

Eliade, M. 1998 Myth and Reality, New York: Waveland.

Elliot, S. 2009 "Coors Light Uses Cold to Turn Up Heat on Rivals," The New York Times, April

27.http://www.nytimes.com/2009/04/27/business/media/27adnewslet ter1.html? $\mathrm{r}=0$

Farb, P., and G. Armelagos 1980 Consuming Passions: The Anthropology of Eating, Boston: Houghton Mifflin.

Feld, S. 1982 Sound and Sentiment, Philadelphia: University of 
Pennsylvania Press.

Feld, S., and K. Basso, eds. 1996 Senses of Place, Santa Fe: School of American Research.

Geertz, C. 1981 Negara: The Theatre State in Nineteenth-Century Bali. Princeton: Princeton University Press.

Geurts, K.L. 2002 Culture and the Senses, Berkeley: University of California Press.

Gibson, J.J. 1979 The Ecological Approach to Visual Perception, Boston: Houghton Mifflin.

Goffman, E. 1959 The Presentation of Self in Everyday Life, New York: Doubleday.

Goffman, E. 1967 Interaction Ritual: Essays on Face-to-Face Behavior, New York: Doubleday.

Graburn, N.H. 1977 “Tourism: The Sacred Journey," in Hosts and Guests: The Anthropology of Tourism, ed. Valene Smith, Philadelphia: The University of Pennsylvania Press, 17-32.

Graburn, N. 1983 "The Anthropology of Tourism," Annals of Tourism Research, 10:9-33.

Grimes, R. 1995 Readings in Ritual Studies, Englewood Cliffs, NJ: PrenticeHall.

Hall, E.T. 1983 The Dance of Life, New York: Anchor Press Doubleday. Guinness Storehouse - Fact sheet. Guinness.archives@diageo.com Hallam, E., and T. Ingold, 2007 Creativity and Cultural Improvisation, London: Berg.

Hertzfeld, M. 2001 Anthropology: Theoretical Practice in Culture and Society, Oxford: Blackwell.

Hirschman, E.C. 1987 "Theoretical Perspectives of Time Use: Implications for Consumer Research," Research in Consumer Behavior, 2:55-81.

Horst, H., and D. Miller, eds. 2012 Digital Anthropology, London: Berg. Howes, D. 2003 Sensual Relations, Ann Arbor: University of Michigan Press.

Howes, D. 2005 Empire of the Senses, Oxford: Berg publishers.

Howes, D. 2007 "Multi-Sensory Marketing in Cross-Cultural Perspective (part I), From Synergy to Synesthesia," Percepnet-Ciencia, January 22, http://www.percepnet.com/cien01 07 ang.htm

Howes, D. 2009 The Sixth Sense Reader, Oxford: Berg.

Howes, D., ed. 1991 The Varieties of Sensory Experience, Toronto:

University of Toronto Press. 
Howes, D., and C. Classen 2013 Ways of Sensing: Understanding the Senses in Society, New York: Routledge.

Hsu, E. 2008 "The Senses and the Social: an Introduction," Ethnos, 73 (4):433-443.

Hultén, B., N. Broweus, and M. Van Dijk (2009), Sensory Marketing, Hampshire: Palgrave MacMillan.

Ingold, T. 2000 The Perception of the Environment, New York: Routledge.

Ingold, T. 2013 Making: Anthropology, Archaeology, Art and Architecture, New York: Routledge.

Jones, C. 2006 Sensorium, Embodied Experience, Technology and Contemporary Art, Cambridge: MIT Press.

Joy, A., and J.F. Sherry 2003 "Speaking of Art as Embodied Imagination: A Multisensory Approach to Understanding Aesthetic Experience," Journal of Consumer Research, 30:259-82.

Kertzer, D. 1989 Ritual, Politics and Power, New Haven, CT: Yale.

Kozinets, R. 2002 “Can Consumers Escape the Market? Emancipatory Illuminations from Burning Man," Journal of Consumer Research, 29:2038.

Kozinets. R. 2009 Netnography: Doing Ethnographic Research Online, New York: Sage Publications.

Krishna, A. 2012 “An Integrative Review of Sensory Marketing: Engaging the Senses to Affect Perception, Judgment and Behavior," Journal of Consumer Psychology, 22:332-351.

Krishna, A., M. Lwin, and M. Morrin 2010 "Product Scent and Memory," Journal of Consumer Research, 37:57-67.

Krishna, A., ed. 2010 Sensory Marketing: Research on the Sensuality of Products, New York: Routledge.

Krishna, A., R. Elder, and C. Caldara 2010 "Feminine to Smell But Masculine to Touch? Multisensory Congruence and its Effect on the Aesthetic Experience," Journal of Consumer Psychology, 20:410-418.

Lakoff, G., and M. Johnson 1999 Philosophy in the Flesh: The Embodied Mind and its Challenge to Western Thought, New York: Basic.

Latham, R., and S. Sassen, eds. 2005 Digital Formations, IT and New Architectures in the Global Realm, Princeton: Princeton University Press.

Latour, B. 2007 Reassembling the Social: An Introduction to Actor Network Theory, Oxford: Oxford University Press.

Malefyt, T. de Waal, and R.J. Morais 2010 "Creativity, Brands and the Ritual Process: Confrontation and Resolution in Advertising Agencies," Culture and Organization, 16:333-347. 
Malnar, J.M., and F. Vodvarka 2004 Sensory Design, Minneapolis: University of Minnesota Press.

MacCannell, D. 1976 The Tourist, New York: Schocken.

Miller, D. 2009 "Buying Time," in Time, Consumption and Everyday Life, Practice Materiality and Culture, eds. E. Strove, F. Trentmann, and R. Wilk, Oxford: Berg, 157-169.

Miller, D., ed. 1995 Unwrapping Christmas, Oxford: Oxford University Press.

Mitchell, D., B. Kahn, and S. Knasko 1995 “There's Something in the Air: Effects of Congruent or Incongruent Ambient Odor on Consumer Decision Making," Journal of Consumer Research, 22:229-238.

Moeran, B. and L. Skov 1995 "Cinderella Christmas: Kitsch, Consumerism and Youth in Japan," in Unwrapping Christmas, Oxford: Oxford University Press, 105-133.

Morrin, M., and S. Ratneshwar 2000 "The Impact of Ambient Scent on Evaluation, Attention, and Memory for Familiar and Unfamiliar Brands," Journal of Business Research, 49 (2):157-165.

Morrin, M., and S. Ratneshwar 2003 "Does It Make Sense to Use Scents to Enhance Brand Memory?" Journal of Marketing Research, 40:10-25.

Oakdale, S. 2009 "Ritual and the Circulation of Experience: Negotiating Community in the Twentieth-century Amazon," in Ritual Communication, eds. Gunter Senft and Ellen Basso, Oxford: Berg, 153-170.

Paivio, A. 1971 Imagery and Verbal Processes, New York: Holt, Rinehart, and Winston.

Paivio, A. 2007 Mind and Its Evolution: A Dual Coding Theoretical Interpretation, Mahwah, NJ: Lawrence Erlbaum Associates, Inc.

Pink, S. 2009 Doing Sensory Ethnography, London: Sage.

Pink, S. 2004 Home Truths, Oxford: Berg.

Pollan, M. 2008 In Defense of Food, New York: Penguin.

Postrel, V. 2003 The Substance of Style, New York: Harper-Collins.

Privette, G. 1983 "Peak Experience, Peak Performance, and Flow: A Comparative Analysis of Positive Human Experiences," Journal of Personality and Social Psychology, 45(6), 1361-1368.

Rappaport, R. 1979 Ecology, Meaning and Religion, Richmond, CA: North Atlantic.

Rodaway, P. 1994 Sensuous Geographies, London: Routledge.

Rook, D. 1985 “The Ritual Dimension of Consumer Behavior," Journal of Consumer Research, 12:251-264.

Schifferstein, H., and C. Spence 2007 "Multisensory Product Experience," 
in Product Experience, eds. H. Schifferstein and P. Hekkert, New York: Elsevier, 133-161.

Schechner, R. 2002 Performance Studies: An Introduction, New York: Routledge.

Schechner, R. 2007 "Rasaesthetics," in The Senses in Performance, eds. S. Banes and A. Lepecki, New York: Routledge, 10-28.

Senft, G., and E. Basso, eds. 2009 Ritual Communication, Oxford: Berg. Seremetakis, N., ed. 1994 The Senses Still. Boulder, CO: Westview.

Sherry, J.F. 1983 "Gift Giving in Anthropological Perspective," Journal of Consumer Research, 10:157-168.

Sherry, J.F. 1990 "A Sociocultural Analysis of a Midwestern American Flea Market," Journal of Consumer Research, 17:13-30.

Sheets-Johnstone, M. 1999 The Primacy of Movement, Amsterdam: John Benjamins.

Spangenberg, E., A. Crowley, and P. Henderson 1996 "Improving the Store Environment: Do Olfactory Cues Affect Evaluations and Behavior?" Journal of Marketing, 60 (April), 67-80.

Spence, C. 2002 The ICI Report on the Secret of the Senses, London: The Communication Group.

Stein, B.E., and M.A. Meredith 1993 The Merging of the Senses. Cambridge: MIT press.

Stoller, P. 1989 The Taste of Ethnographic Things. Philadelphia: University of Pennsylvania Press.

Stoller, P. 1997 Sensuous Scholarship, Philadelphia: University of Pennsylvania Press.

Strove, E., F. Trentmann, and R. Wilk, eds. 2009 Time, Consumption and Everyday Life. Oxford: Berg.

Synnott, A. 1991 "Puzzling Over the Senses: From Plato to Marx," in The Varieties of Sensory Experience, ed. D. Howes, Toronto: University of Toronto press, 239-256.

Synnott, A. 1993 The Body Social. New York: Routledge.

Thompson, C. and G. Coskuner-Balli 2007 “Countervailing Market Responses to Corporate Co-optation and the Ideological Recruitment of Consumption Communities," Journal of Consumer Research, 34:135-152.

Turner, V. 1967 The Forest of Symbols, Ithaca, NY: Cornell University Press.

Turner, V. 1969 The Ritual Process, New York: Aldine.

Vannini, P., D. Waskul, and S. Gottschalk 2012 The Senses in Self, Society, and Culture, London: Routledge. 
Wallendorf, M., and E.J. Arnould 1991 "'We Gather Together':

Consumption Rituals of Thanksgiving Day," Journal of Consumer Research, 18:13-31.

Wulff, H. 2011 "Ways Of Seeing Ireland's Green: From Ban to the Branding of a Nation," Paper presented at the Annual Meeting of the American Anthropological Association, Montreal, Canada, 16-20, November.

Zerubavel, E. 1981 Hidden Rhythms: Schedules and Calendars in Social Life. Chicago: University of Chicago Press.

Timothy de Waal Malefyt is Clinical Associate Professor at Fordham University Business School in NYC. Previously, he worked in advertising for over 15 years as Director of Cultural Discoveries for BBDO Worldwide advertising in NYC, and at D'Arcy, Masius, Benton \& Bowles in Detroit. He holds a Ph.D. in anthropology from Brown University, is coeditor of Advertising Cultures (2003), co-author of Advertising and Anthropology (2012), and was co-chair of EPIC conference for 2013. He is frequently cited in Business Week, The New York Times, USA TODAY, and other media. He may be reached at timothy.malefyt@gmail.com 